\title{
Methylation pattern of $\mathrm{H} 19$ exon 1 is closely related to preeclampsia and trophoblast abnormalities
}

\author{
LINSHAN LU ${ }^{1 *}$, ZHENG HOU $^{2 *}$, LI LI $^{3 *}$, YANHONG YANG $^{1}$, XIAOHONG WANG ${ }^{1}$, BEILEI ZHANG ${ }^{1}$,

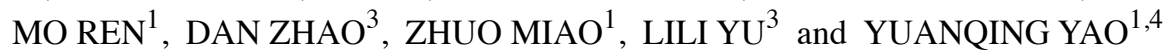 \\ ${ }^{1}$ Department of Obstetrics and Gynecology, Tangdu Hospital, ${ }^{2}$ Department of Pharmacology, School of Pharmacy, \\ Fourth Military Medical University, Xi'an, Shaanxi; ${ }^{3}$ Department of Obstetrics and Gynecology, \\ Research Institute of Surgery and Daping Hospital, Third Military Medical University, Chongqing, Sichuan; \\ ${ }^{4}$ Department of Obstetrics and Gynecology, General Hospital of the Chinese People's Liberation Army, Beijing, P.R. China
}

Received December 24, 2013; Accepted June 6, 2014

DOI: $10.3892 /$ ijmm.2014.1816

\begin{abstract}
Preeclampsia (PE) is a pregnancy-induced disorder characterized by the overproliferation of trophoblasts. Hydatidiform moles, which are associated with a high risk of developing PE, are characterized by the excessive proliferation of trophoblastic tissue. $\mathrm{H} 19$ is highly expressed in placental tissue; however, its biological function remains unclear. A fundamental modification of the $\mathrm{H} 19$ gene is DNA methylation, which typically occurs in CG-rich regions at the promoter or the first exon region. In this study, in order to investigate the DNA methylation pattern of the $H 19$ exon 1 region in placental tissues and trophoblast cells, placental specimens were collected from women in the first trimester of pregrancy (FTP) and the third trimester of pregnancy (TTP), as well as from from women with severe preeclampsia (sPE). We found that the DNA methylation levels of $\mathrm{H} 19$ exon 1 were significantly higher in the tissues obtained from women in TTP than from those obtained from women in FFP. The methylation status of CpG 1 sites within exon 1 of $H 19$ was markedly higher in the placental tissues obtained from women with sPE than in the tissues obtained from women in TTP. In addition, we used the human choriocarcinoma cell line, JEG-3, and treated the cells with the methylation inhibitor, 5-aza-2'-deoxycytidine (5-Aza-Dc). Following treatment with 5-Aza-Dc, the methylation levels at this $\mathrm{CpG}$ site showed marked hypomethylation. In addtion, the cell proliferative,
\end{abstract}

Correspondence to: Professor Yuanqing Yao, Department of Obstetrics and Gynecology, Tangdu Hospital, Fourth Military Medical University, 1 Xinsi Road, Xi'an, Shaanxi 710038, P.R. China Email: yyqyao@yeah.net

Professor Lili Yu, Department of Obstetrics and Gynecology, Daping Hospital, 10 Changjiang Zhilu, Chongqing, Sichuan 400042, P.R. China

Email: lililiyuyu@sina.com

${ }^{*}$ Contributed equally

Key words: preeclampsia, $H 19$ exon 1, DNA methylation, 5-aza-2'deoxycytidine migratory and invasive capacities of the cells were remarkably inhibited. Our data suggest that hypermethylation at individual CpG sites within exon 1 of $H 19$ may be involved in the dysfunction of trophoblasts and the pathogenesis of PE.

\section{Introduction}

The placenta, a unique endocrine organ during pregnancy, plays a critical role in embryonic and fetal development. The main functions of the placenta are executed by trophoblasts, which originate from the trophectoderm layer of the blastocyst. During morula-to-blastocyst transition, the surface cells become trophoblasts and give rise to extraembryonic structures, including the placenta (1). The trophoblast, which behaves like a 'pseudotumor', proliferates, differentiates, migrates and invades the endometrium in a controlled manner (2). However, implantation and placentation are strictly regulated in time and space; they are intimately linked to and enable the embryo to be anchored to the uterine wall, and thus ensure a normal pregnancy and fetal growth through the placenta. Any abnormal factors promoting or inhibiting this process may cause pregnancy-related diseases. One of these diseases is preeclampsia (PE).

As one of the first imprinted genes, the $H 19$ gene was initially isolated in 1984 (3) and further cloning and sequence determination was carried out in 1988 (4). This gene is composed of 5 exons and 4 small introns (4). H19 RNA is transcribed by RNA polymerase II, then spliced and exported into the cytoplasm. Due to the lack of a long conserved open reading frame between the murine and human genome, the product of H19 appears to be a non-coding RNA (5). The allele-specific expression profile of the $H 19$ gene in human placental tissue may result from dynamic alternations during fetal development (6). The $H 19$ gene is highly expressed during mammalian embryonic development (7).

In the murine placenta, the $H 19$ gene is the second most abundant transcript (7), which is activated in the cells of the trophectoderm at the time of implantation (8) and accumulates to extremely high levels in the cells. These cells exclusively ontribute to the formation of extraembryonic tissue. Moreover, the $H 19$ transcript from human placental tissue during the first and third trimester may play a regulatory role in trophoblast 
differentiation (9). In a previous study of ours, we indicated that the knockdown of $H 19$ inhibits the proliferation and apoptosis of human trophoblast-derived choriocarcinoma cells (10). Besides, the lack of $H 19$ gives rise to placental overgrowth (7). Thus, the pattern of $H 19$ expression suggests that it may regulate the function of trophoblasts during the stage of embryogenesis and placental development. We thus hypothesized that exon 1 is the longest exon and functional region of the $\mathrm{H} 19$ gene, which may contribute to the modulation and function of the placenta via trophoblasts.

The methylation patterns of specific genes have been found to undergo dynamic changes in the germ line and early embryo (11). Variations in DNA methylation are involved in the developmental process occurring in normal and abnormal human placentas (12). The demethylating agent, 5-azacytidine, has been shown to change methylation profiles in pregnant rats and to induce a marked reduction in placental growth (13). Using methylation-sensitive high resolution melting, Gao et al found that the promoter region of the $H 19$ gene was hypermethylated in early-onset PE placentas compared with third-trimester normal controls (14). Moreover, the H19 promoter and exon 1 were differentially methylated in embryonic and somatic tissues in mice (15).

Although our understanding of the intricate role of the $\mathrm{H} 19$ gene in the regulation of the placental function in mice has improved, the methylation status of $H 19$ exon 1 in human placental development and trophoblast function remains unclear. Furthermore, little is known about the temporal methylation variation of $H 19$ exon 1 across gestation, and whether the methylation status in the region is stable throughout the first trimester and during the later stages of gestation. Thus, in the present study, we aimed to assess the DNA methylation pattern of $H 19$ exon 1 in trophoblasts and human placental tissues obtained from women undergoing normal pregnancy and in pregnant women withPE.

\section{Materials and methods}

Subjects and sample collection. The experimental protocols in this study were reviewed and approved by the Institutional Review Boards of the corresponding hospitals and written informed consent was obtained from all participants. A total of 37 subjects (21-39 years old) at different stages of gestation were recruited from outpatient and inpatient services at the Department of Obstetrics and Gynecology, Daping Hospital, Xinan Hospital and Xinqiao Hospital of the Third Military Medical University, the First Affiliated Hospital of Chongqing Medical University and the Reproductive Centre of the District of Banan, Chongqing, China, from August 2007 to March 2008. Six subjects in the first trimester of pregnancy (FTP), 16 subjects in the third trimester of pregnancy (TTP) and 15 women with severe PE (sPE) were included in the present study. The placental villous tissues from women undergoing normal pregnancy between 6 and 9 weeks of gestation were collected during the procedure of induced abortion, while the placental tissues from women undergoing normal full-term pregnancy or from women with sPE in the third trimester were obtained by cesarean section. Patients with SPE were diagnosed according to the criteria stated in the American College of Obstetricians and Gynecologists (ACOG) Practice Bulletin (2002), which included blood pressure of $\geq 160 / 110 \mathrm{mmHg}$ on 2 occasions at least $6 \mathrm{~h}$ apart after 20 weeks of gestation and proteinuria ( $\geq 5 \mathrm{~g} / 24 \mathrm{~h}$ or $\geq 3+$ on 2 random urine samples collected at least $4 \mathrm{~h}$ apart). Patients with a history of chronic hypertension, diabetes mellitus, nephropathy or a recent urinary tract infection were excluded from this study. All the specimens were quickly dissected, snap-frozen in liquid nitrogen and stored at $-80^{\circ} \mathrm{C}$ until further analyses.

Cell culture. The human choriocarcinoma cell line, JEG-3, was obtained from the American Type Culture Collection (ATCC, Mannasas, VA, USA). The cells were cultured in Dulbecco's modified Eagle's medium/nutrient mixture F-12 medium (DMEM/F-12; Gibco-BRL, Carlsbad, CA, USA) supplemented with $10 \%$ fetal bovine serum (FBS; Gibco-BRL) at $37^{\circ} \mathrm{C}$ in a humidified atmosphere containing $5 \% \mathrm{CO}_{2}$. To assess the effects of methylation inhibition, the cells were treated with 5-aza-2'-deoxycytidine (5-Aza-Dc; Sigma-Aldrich, St. Louis, MO, USA).

DNA methylation assay. The cells were pelleted following treatment with 5-Aza-Dc at concentrations of 1,10 , or $100 \mu \mathrm{mol} / 1$ for 24,48 and $72 \mathrm{~h}$. Cells treated with $0.05 \%$ DMSO were used as controls. Genomic DNA was extracted from the cells or frozen tissues using the phenol-chloroform method. The bisulphite conversion of DNA was performed using a EZ DNA Methylation-Gold ${ }^{\mathrm{TM}}$ kit (Zymo Research, Orange, CA, USA) following the manufacturer's instructions. DNA methylation analysis was conducted following bisulfite sequencing PCR (BSP). The bisulfite sequence of the primers was as follows: 5'-TTGGAGTTTGGTAGGAGTGATG-3' (forward) and 5'-CCCAAACCCTAAAATCAAACCCT-3' (reverse). PCR amplification was conducted under the following conditions: $94^{\circ} \mathrm{C}$ for $5 \mathrm{~min}$, then 34 cycles of $94^{\circ} \mathrm{C}$ for $30 \mathrm{sec}$, $61^{\circ} \mathrm{C}$ for $30 \mathrm{sec}, 72^{\circ} \mathrm{C}$ for $1 \mathrm{~min}$, followed by $72^{\circ} \mathrm{C}$ for $10 \mathrm{~min}$ for the final extension. All products were confirmed to be single bands by $2 \%$ agarose gel electrophoresis. PCR products were sequenced by Shanghai Invitrogen Biotechnology Co.,Ltd. (Shanghai, China).

$R N A$ extraction and real-time reverse transcription $P C R$ $(R T-q P C R)$. The cells were treated with 5-Aza-Dc at concentrations of $0.1,1,10$ or $100 \mu \mathrm{mol} / 1$ for 24,48 or $72 \mathrm{~h}$ and pelleted. Cells treated with $0.05 \%$ DMSO were used as controls. Total RNA from the tissues and cells was extracted using TRIzol reagent (Invitrogen Life Technologies, Carlsbad, CA, USA) and reverse transcribed into cDNA using the RT kit (BioBRK, Chengdu, China) according to the manufacturer's instructions. Quantitative (real-time) PCR was performed using the SYBR-Green PCR kit (Takara Bio Inc., Shiga, Japan). The primer sequences were as follows: H19 forward, 5'-GGCAAG AAGCGGGTCTGT-3' and reverse, 5'-GCTGCTGTTCCG ATGGTGT-3'; and GAPDH forward, 5'-ACCCATCACC ATCTTCCAGGAG-3' and reverse, 5'-GAAGGGGCGGAG ATGATGAC-3'.

The reactions in triplicate were first denatured at $94^{\circ} \mathrm{C}$ for $5 \mathrm{~min}$ and then subjected to 35 cycles of $94^{\circ} \mathrm{C}$ for $30 \mathrm{sec}, 59^{\circ} \mathrm{C}$ for $30 \mathrm{sec}$ and $72^{\circ} \mathrm{C}$ for $30 \mathrm{sec}$. Data were normalized to those of $G A P D H$. The relative mRNA level was calculated using the $2^{-\triangle \Delta C t}$ method. 


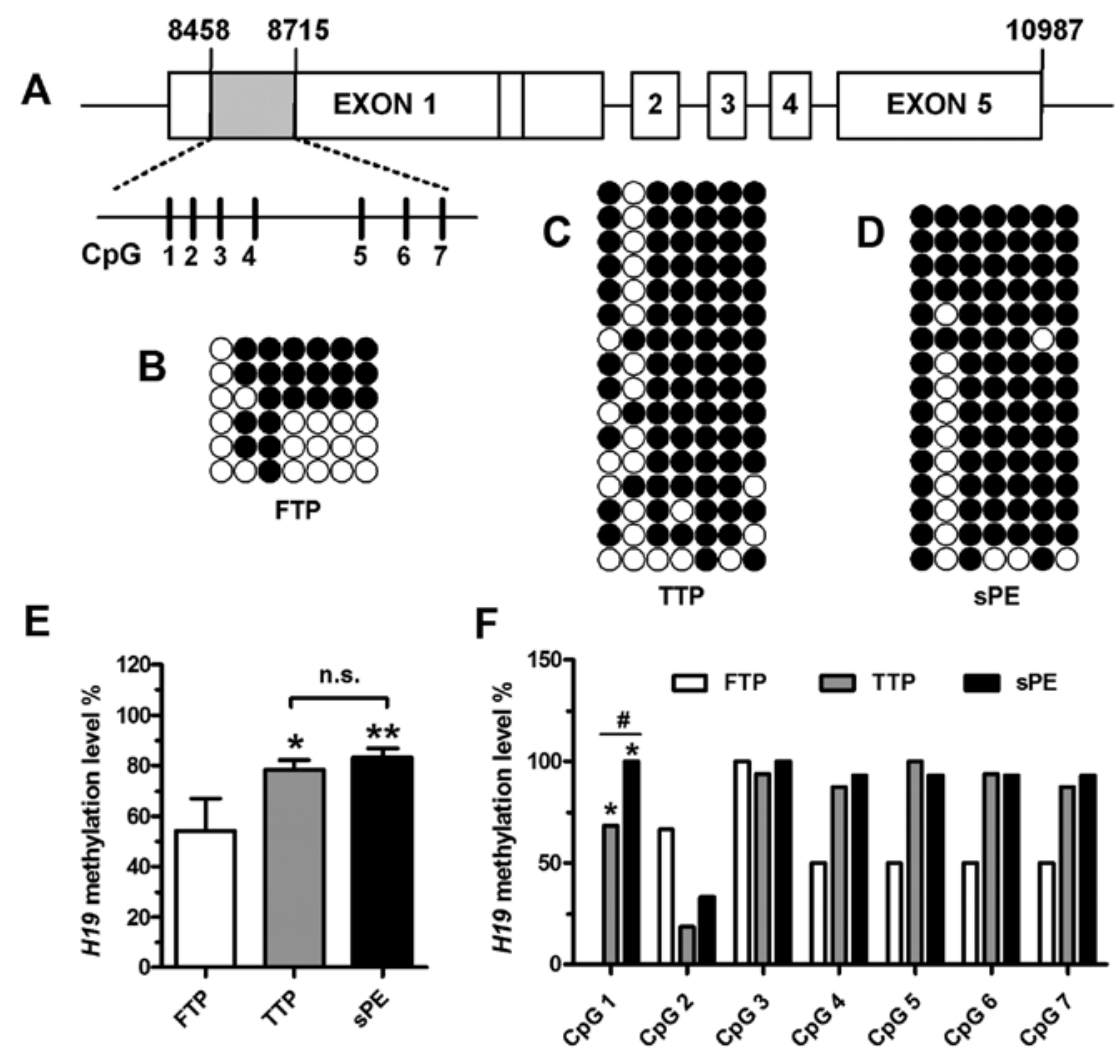

Figure 1. DNA methylation status of $H 19$ exon 1 in placental tissue. (A) Schematic diagram of human $H 19$ exonic region. The region (grey box), containing $7 \mathrm{CpG}$ sites (vertical black bars) of the $\mathrm{H} 19$ exon 1 region was analyzed. Bisulfite sequencing regions are shown with individual CpG sites underneath. Data represent the placental tissue from women in (B) the first trimester of pregnancy (FTP), (C) the third trimester pregnancy (TTP) and (D) women with severe preeclampsia (sPE). Open and closed circles indicate unmethylated and methylated CpG sites, respectively. (E) DNA methylation levels across $7 \mathrm{CpG}$ sites in placental tissue specimens from women in FTP and TTP, as well as from women with sPE. The data are presented as the means \pm standard error of the mean (SEM): ${ }^{*} \mathrm{P}<0.05,{ }^{* *} \mathrm{P}<0.01$ vs. results for FTP. (F) Mean methylation for each $\mathrm{CpG}$ site in placental tissue specimens from women FTP and TTP and women with $\mathrm{SPE}\left({ }^{*} \mathrm{P}<0.05\right.$ vs. results for $\mathrm{FTP},{ }^{*} \mathrm{P}<0.05$ vs. results for TTP).

MTT assay. The effects of 5-Aza-Dc on cell proliferation were determined by MTT assay. The cells $\left(3.5 \times 10^{3}\right.$ cells/well $)$ were seeded in 96-well plates with $100 \mu \mathrm{l}$ DMEM/F-12 with $10 \%$ FBS in each well in sextuplicate for $24 \mathrm{~h}$, and then treated without or with 5-Aza-Dc at concentrations of $0.01,0.1,1,10$ or $100 \mu \mathrm{mol} / 1$ for 24,48 or $72 \mathrm{~h}$. Cells treated with $0.05 \%$ DMSO were used as controls. On the day of the assay, the growth medium was replaced with serum-free medium containing $5 \mathrm{mg} / \mathrm{ml}$ MTT (Sigma-Aldrich) and incubated at $37^{\circ} \mathrm{C}$ for $4 \mathrm{~h}$. At the end of the incubation period, the cells were solubilized in $150 \mu \mathrm{l}$ of DMSO, and colorimetric determination was performed at $570 \mathrm{~nm}$ absorbance with a plate reader. The data are presented as the mean values from 3 independent experiments.

Cell migration and invasion assays. A cell migration assay were was performed using Transwell inserts $(6.5 \mathrm{~mm}$ diameter; $8 \mu \mathrm{m}$ pore size polycarbonate membrane; BD Biosciences, Franklin Lakes, NJ, USA). For cell invasion assay, Transwell plates were coated with $50 \mu \mathrm{l}$ Matrigel (1:10 dilution; BD Biosciences) solution per well and dried for $30 \mathrm{~min}$ at $37^{\circ} \mathrm{C}$ with $5 \% \mathrm{CO}_{2}$. Cells $\left(1 \times 10^{5}\right.$ cells/well) in $0.2 \mathrm{ml}$ serum-free medium with or without 5-Aza-Dc $(100 \mu \mathrm{mol} / \mathrm{l})$ were placed in the upper chamber, whereas the lower chamber was loaded with $0.8 \mathrm{ml}$ medium containing $10 \%$ FBS. The cells were allowed to migrate or invade for $24 \mathrm{~h}$ at $37^{\circ} \mathrm{C}$ with $5 \% \mathrm{CO}_{2}$. After removing the upper Transwell, the non-migrated or non-invaded cells on the inner surface of the
Transwell were carefully removed using a cotton swab. The cells that had penetrated to the bottom side of the membrane were then fixed in buffered formalin and stained using haematoxylin. The number of stained cells/well was counted using an inverted microscope (Olympus, Tokyo, Japan).

Statistical analysis. Analysis of variance (ANOVA) or Fisher's exact test was used for statistical analysis. A probability (P)-value $<0.05$ was considered to indicate a statistically significant difference. All statistical analyses were performed using SPSS software version 13.0 or GraphPad Prism version 5.01.

\section{Results}

The methylation status at the $H 19$ exon 1 region in human placental tissue. As shown in Fig. 1A, we used BSP assay to quantitatively measure the levels of methylation at $7 \mathrm{CpG}$ sites (CpG 1, 8,547 bp; CpG 2, 8,558 bp; CpG 3, 8,571 bp; CpG 4, 8,587 bp; CpG 5, 8,637 bp; CpG 6, 8,658 bp; CpG 7, 8,675 bp) in $H 19$ exon 1 (GenBank accession no. AF087017) in human placental tissues obtained from women at different stages of gestation. Methylation levels in the first exon of the $\mathrm{H} 19$ gene in placental tissue from women in FTP (Fig. 1B), TTP (Fig. 1C) and from women with sPE (Fig. 1D) were $54.17 \pm 12.81 \%$, $78.44 \pm 15.63 \%$ and $83.21 \pm 14.33 \%$, respectively. The region showed significant hypomethylation in the placental tissue 
A
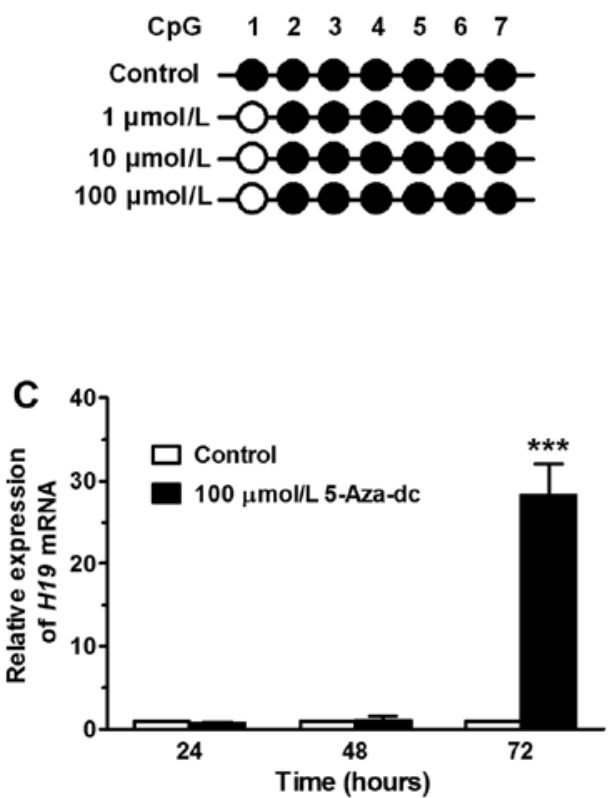
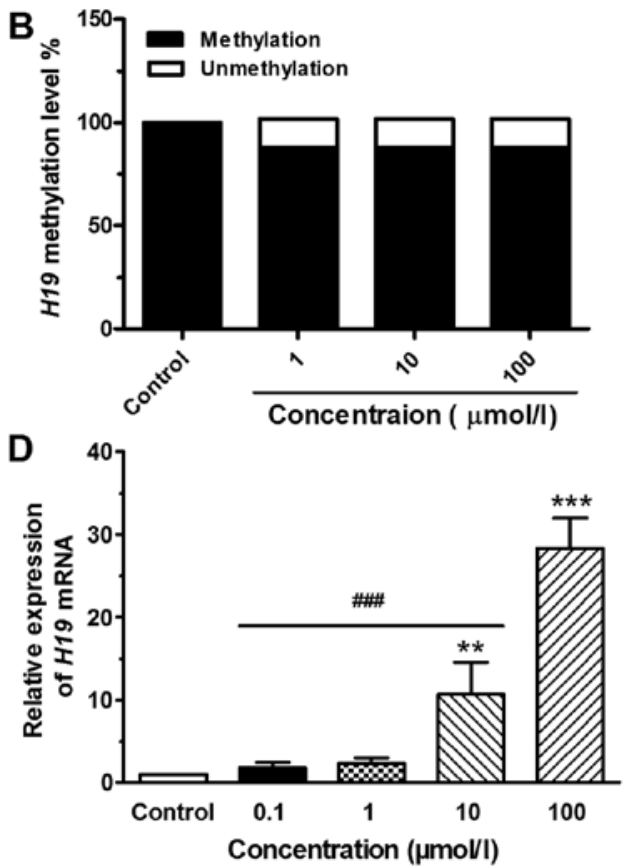

Figure 2. DNA methylation level and $H 19$ mRNA expression in JEG-3 cells. (A) DNA methylation status of individual CpG sites in JEG-3 cells treated with 5-aza-2'-deoxycytidine (5-Aza-Dc) for $72 \mathrm{~h}$. (B) DNA methylation levels of $H 19$ exon 1 across $7 \mathrm{CpG}$ sites in JEG-3 cells from different treatment groups. (C) $H 19$ expression level of JEG-3 cells treated with $100 \mu \mathrm{mol} / 1$ 5-Aza-Dc for 24,48 or $72 \mathrm{~h}$. The data are presented as the means \pm SD: ${ }^{* * *} \mathrm{P}<0.001 \mathrm{vs}$. results for control (DMSO-treated cells). (D) $H 19$ expression level in JEG-3 cells treated with 5-Aza-Dc for $72 \mathrm{~h}$ at concentrations of $0.1,1,10 \mathrm{or} 100 \mu \mathrm{mol} / 1$. The data are presented as the means $\pm \mathrm{SD}:{ }^{* *} \mathrm{P}<0.01,{ }^{* * *} \mathrm{P}<0.001$ vs. results for control; ${ }^{\# \# \#} \mathrm{P}<0.001$ vs. results for $100 \mu \mathrm{mol} / 1$ 5-Aza-Dc treatment.
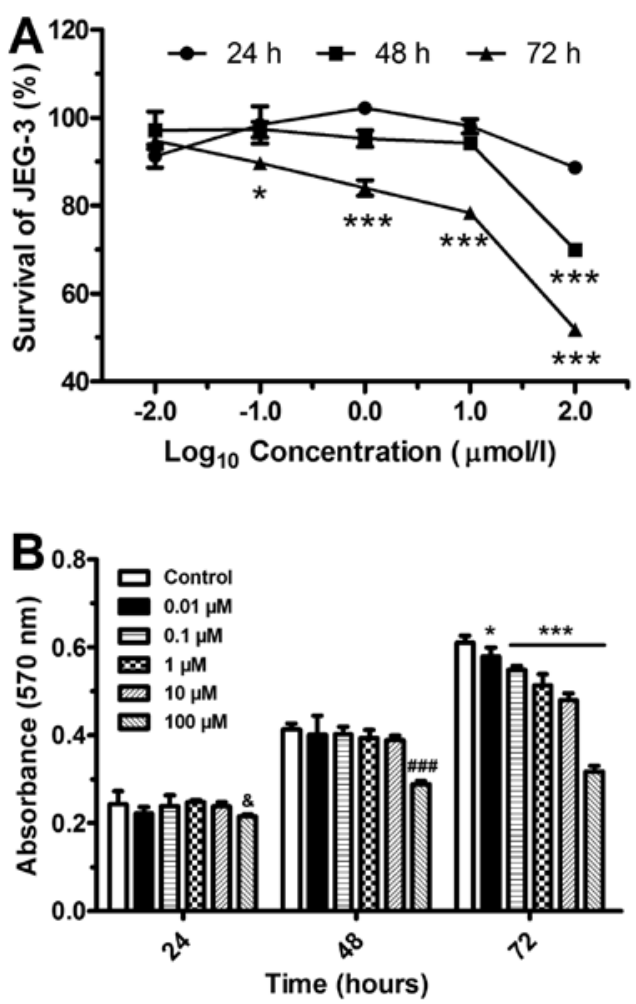

Figure 3. Inhibition of JEG-3 cell proliferation following demethylation treatment. (A) Concentration-response curves of JEG-3 cells treated with 5-aza-2'-deoxycytidine (5-Aza-Dc) at a concentration of $100 \mu \mathrm{mol} / 1$ for 24 , 48 or $72 \mathrm{~h}$. Cell proliferation was determined by MTT assay. The data are presented as the means \pm SEM: ${ }^{*} \mathrm{P}<0.05,{ }^{* * *} \mathrm{P}<0.001$ vs. results for control. (B) The absorbance at $570 \mathrm{~nm}$ of JEG-3 cells following incubation without or with various concentrations of 5-Aza-Dc for 24,48 and $72 \mathrm{~h}$. The data are presented as the means \pm SD: ${ }^{~} \mathrm{P}<0.05$ vs. results for control of $24 \mathrm{~h},{ }^{\# \#} \mathrm{P}<0.001$ vs. results for control of $48 \mathrm{~h} ;{ }^{*} \mathrm{P}<0.05,{ }^{* * * *} \mathrm{P}<0.001$ vs. results for control of $72 \mathrm{~h}$. from women in FTP compared with that from women in TTP or women with sPE $(\mathrm{P}<0.05)$ (Fig. 1E). When each $\mathrm{CpG}$ site was analyzed independently, the methylation level at $\mathrm{CpG} 1$ of $H 19$ exon 1 displayed significant demethylation in the placental tissue from women in FTP in comparison to that from women in TTP $(\mathrm{P}<0.01)$ (Fig. 1F). The methylation levels at this site of $H 19$ were significantly increased in the placental tissue from women with sPE compared with the levels in the placental tissue from women in TTP $(\mathrm{P}<0.01)$.

Methylation level of the $H 19$ exon 1 region in JEG-3 cells treated with 5-Aza-Dc. The chemical agent, 5-Aza-Dc, a cytidine analog, has been reported to effectively result in the demethylation of DNA (16). In this study, the region (H19 exon 1) containing 7 CpG sites, spanning 258 bp, was analyzed (Fig. 2A). DNA from the JEG-3 cells treated without or with 5-Aza-Dc at concentrations of 1,10 or $100 \mu \mathrm{mol} / 1$ was extracted at $72 \mathrm{~h}$ and then analyzed by BSP assay. The methylation level of the exon 1 region was signaficantly demethylated in the cells treated with 5-Aza-Dc compared with the control (DMSO-treated) cells, and the effect was dose-independent (Fig. 2B). However, the demethylation effect of 5-Aza-Dc was only observed at the $\mathrm{CpG} 1$ site and not at the other $6 \mathrm{CpG}$ sites (Fig. 2A).

Expression level of H19 in JEG-3 cells treated with 5-Aza-Dc. Subsequently, we examined whether H19 exon 1 demethylation leads to an increase in the $H 19$ mRNA level in JEG-3 cells. Following treatment with 5-Aza-Dc at $100 \mu \mathrm{mol} / 1$ for 24,48 or $72 \mathrm{~h}$, the $H 19$ mRNA expression was $0.71 \pm 0.07,1.05 \pm 0.49$ and $28.35 \pm 3.72$, respectively (Fig. 2C). Following treatment for $72 \mathrm{~h}$ with 5-Aza-Dc at concentrations of $0.1,1,10$ or $100 \mu \mathrm{mol} / 1$, the 
A
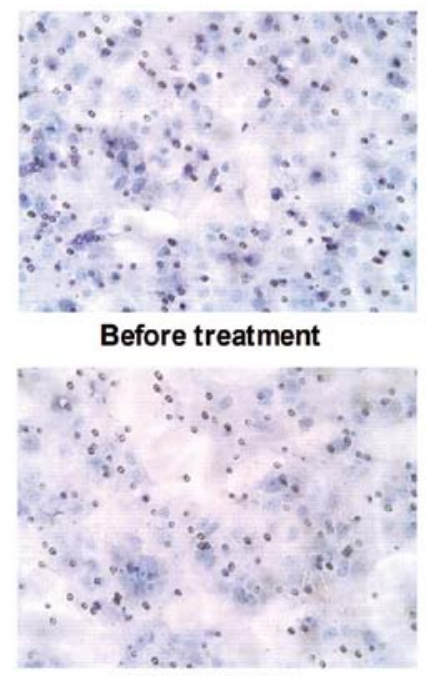

After treatment

B

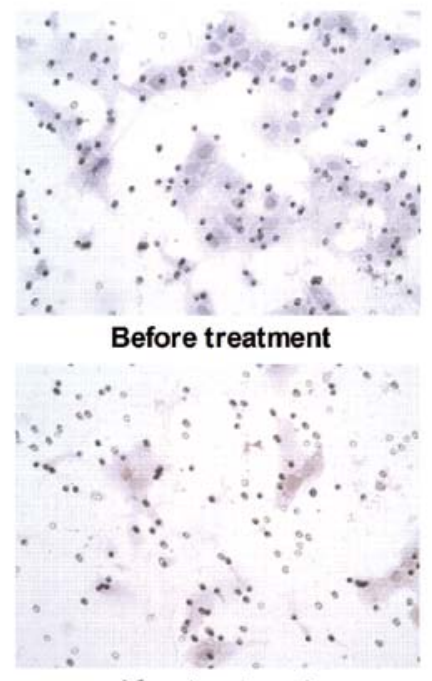

After treatment
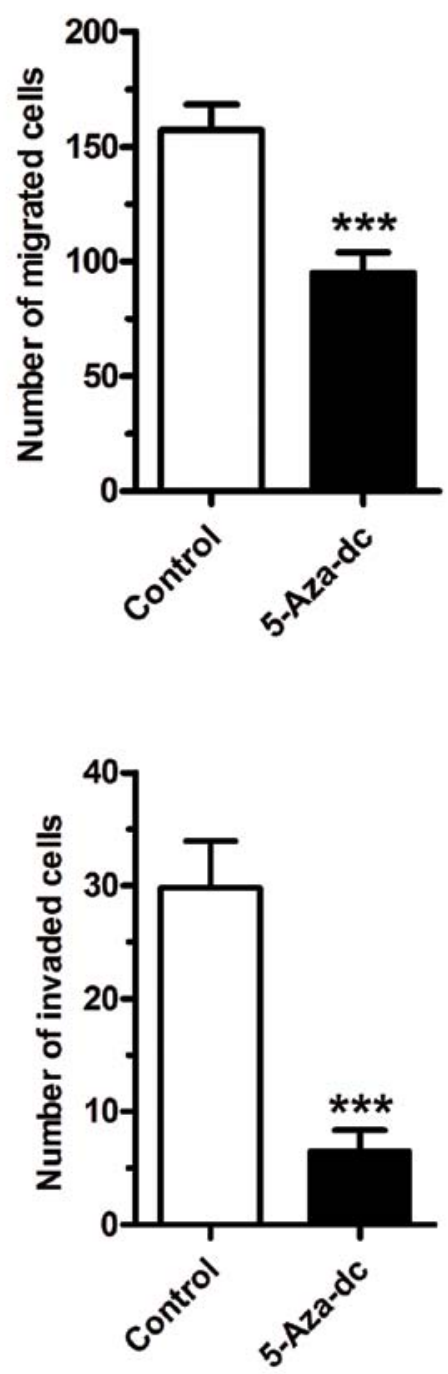

Figure 4. Inhibition of JEG-3 cell migration and invasion following demethylation treatment. (A) Migration of JEG-3 cells in the absence or presence of 5-aza2'-deoxycytidine (5-Aza-Dc) at $100 \mu \mathrm{mol} / 1$ for $24 \mathrm{~h}$. Migrated cells were examined with hematoxylin staining (original magnification, x200) and then quantified by manual counting. The data are presented as the means $\pm \mathrm{SD}:{ }^{* * *} \mathrm{P}<0.001$ vs. results for control. (B) Invasion of JEG-3 cells in the absence or presence of 5-Aza-Dc at $100 \mu \mathrm{mol} / \mathrm{l}$ for $24 \mathrm{~h}$. Invaded cells were examined with hematoxylin staining (original magnification, $\mathrm{x} 200$ ) and then quantified by manual counting. The data are presented as the means $\pm \mathrm{SD}:{ }^{* * * *} \mathrm{P}<0.001$ vs. results for control.

H19 mRNA expression was $1.82 \pm 0.64,2.32 \pm 0.69,10.70 \pm 3.89$ and $28.35 \pm 3.72$, respectively (Fig. 2D). As the treatment time or concentration increased, a marked increase in H19 expression was observed.

Inhibition of cell proliferation by 5-Aza-Dc. We then investigated JEG-3 cell viability following treatment with 5-Aza-Dc at various concentrations and different periods of time points. Cell proliferation was suppressed in a concentration-dependent manner (Fig. 3A). In comparison to the control (DMSOtreated) group, the cells treated for 24 and $48 \mathrm{~h}$ displayed a significant inhibition of proliferation at the concentration of $100 \mu \mathrm{mol} / 1(\mathrm{P}<0.001)$ (Fig. 3B). By contrast, the proliferation of the cells treated for $72 \mathrm{~h}$ with various concentrations of 5-Aza-Dc was significantly inhibited.

Demethylation by 5-Aza-Dc inhibits trophoblast-derived cell migration and invasion. The effects of 5-Aza-Dc on the migratory and invasive properties of JEG-3 cells were then examined. Following treatment with 5-Aza-Dc at $100 \mu \mathrm{mol} / 1$ for $24 \mathrm{~h}$, both the migration (Fig. 4A) and invasion (Fig. 4B) abilities of the JEG-3 cells were markedly inhibited $(\mathrm{P}<0.001)$.

\section{Discussion}

The placenta is a unique endocrine organ during pregnancy that, although it is only transiently required, plays a critical role in protecting and nourishing the growing fetus (17). Trophoblasts developing into placental tissue are exclusive to this type of tissue. During normal gestation, these trophoblasts act as tumor-like cells, with enhanced proliferative and invasive activities, but behave in a moderate and balanced way (2). Once this balance is broken, corresponding diseases may occur. Excessive invasion may lead to invasive moles or choriocarcinoma (18). On the other hand, poor invasion may cause obstetric complications, including miscarriage, intra- 
uterine growth restriction and PE (19). PE is a life-threatening, pregnancy-specific disorder characterized by hypertension and proteinuria (20). It is generally agreed that the presence of the placenta, and more specifically the presence of trophoblasts, is a major cause of this disorder (17). Elucidating the modulation of trophoblast development is key to understanding the pathogenesis of PE.

Previous studies on DNA methylation of the $H 19$ gene have mainly focused on the imprinting control region (ICR), the $H 19$ promoter region, or the $H 19$ transcription start site (21-23). In the present study, we investigated the methylation status of H19 exon 1 in placental tissue from women undergoing normal pregnancy during the first and third trimesters, as well as pregnant women with PE. As one of the first imprinted genes (3), the $H 19$ transcript is abundantly expressed in mouse placental tissue and human intermediate trophoblasts and cytotrophoblasts. Mice that carry a deletion of $H 19$ display placental overgrowth (7). In a previous study of ours, we demonstrated that the $H 19$ gene imprinting status in human placental tissue is markedly altered during normal pregnancy, but imprinting is lost in the placental tissue of PE patients (24). These differences suggest that epigenetic changes in the $H 19$ gene may be relevant to the pathogenesis of PE. DNA methylation is fundamental for epigenetic modulation in mammalian development (25). It typically occurs at the $\mathrm{C} 5$ position of cytosine residues in a $\mathrm{CpG}$ dinucleotide context. CG-rich regions, known as $\mathrm{CpG}$ islands, most often localize at the promoter and exon 1 regions (26). $H 19$ exon 1 is highly conserved in both marsupials and eutherians (27), suggesting that this region may play some unknown important role in mammalian development.

In this study, we assessed the methylation status in H19 exon 1 in placental tissue from women in FTP, TTP, as well as in pregnant women with SPE by BSP. We found that the DNA methylation level of $H 19$ exon 1 was significantly increased in placental tissue from women in TTP in comparison to that in placental tissue from women in FTP. It was observed that, compared with the placental tissue from women in TTP, the methylation levels in placental tisssue from women with $\mathrm{SPE}$ were only slightly enhanced in this region $(\mathrm{P}>0.05)$ (Fig. 1E). We further analyzed the methylation status of each $\mathrm{CpG}$ site independently. The methylation levels at the $\mathrm{CpG} 1$ site were significantly increased in the placental tissue from women in TTP in comparison to those in placental tissue from women in FTP. More importantly, hypermethylation at the $\mathrm{CpG} 1$ site was markedly increased in the placental tissue from women with sPE when compared with the placental tissue from women in TTP (Fig. 1F). These results indicate that the methylation levels of $H 19$ exon 1 in the human placenta are dynamically altered during gestation. Furthermore, there was marked hypermethylation at individual $\mathrm{CpG}$ sites of $\mathrm{H} 19$ exon 1 in the placental tissue from women with PE. Hence, the alteration of the methylation status in individual $\mathrm{CpG}$ sites may be associated with abnormal placentation and the pathogenesis of PE.

In this study, to investigate the effects of demethylation on trophoblasts, 5-Aza-Dc, a cytidine analog, we used as a DNA methylation inhibitor. The CpG 1 site rather than the other sites in this region showed marked demethylation in the treated cells (Fig. 2A and B). These results indicated that the demethylation agent, 5-Aza-Dc, does not act on each $\mathrm{CpG}$ site but on some individual positions in DNA sequences. Besides, the relative expression of $H 19$ mRNA increased following treatment of the trophoblasts with 5-Aza-Dc (Fig. 2C and D), indicating that demethylation at some individual $\mathrm{CpG}$ sites may correlate with the enhanced mRNA expression of $H 19$.

Originating from trophoblasts, the hydatidiform mole has a propensity to malignancy. The expression of $H 19$ has been shown to be decreased during the transition from a complete hydatidiform mole to choriocarcinoma (28), which indicates an inhibitory role for $\mathrm{H} 19$ during the malignant transformation of trophoblastic diseases. This is consistent with our present results that the proliferation (Fig. 3), migratory and invasive (Fig. 4) abilities of the choriocarcinoma cells were suppressed following demethylation treatment, which induced the upregulation of $\mathrm{H} 19$ expression.

In conclusion, in this study, we demonstrate that the $\mathrm{CpG} 1$ site in $\mathrm{H} 19$ exon 1 is hypermethylated in placental tissue from pregnant women with PE. Following treatment of the cells with the methylation inhibitor, 5-Aza-Dc, the methylation levels at this site in the trophoblasts were markedly decreased and the mRNA levels of the $H 19$ gene were increased. Furthermore, the proliferative, migratory and invasive abilities of the trophoblasts were significantly inhibited. Therefore, our data suggest that hypermethylation at the $\mathrm{CpG} 1$ site of $\mathrm{H} 19$ exon 1 may be associated with the overproliferation of trophoblasts and may contribute to the pathogenesis of PE.

\section{Acknowledgements}

This study was supported by grants from the National Natural Science Foundation of China (nos. 81070505 and 81070496).

\section{References}

1. Red-Horse K, Zhou Y, Genbacev O, et al: Trophoblast differentiation during embryo implantation and formation of the maternal-fetal interface. J Clin Invest 114: 744-754, 2004

2. Merviel P, Carbillon L, Challier JC, Rabreau M, Beaufils M and Uzan S: Pathophysiology of preeclampsia: links with implantation disorders. Eur J Obstet Gynecol Reprod Biol 115: 134-147, 2004.

3. Pachnis V, Belayew A and Tilghman SM: Locus unlinked to alpha-fetoprotein under the control of the murine raf and Rif genes. Proc Natl Acad Sci USA 81: 5523-5527, 1984.

4. Pachnis V, Brannan CI and Tilghman SM: The structure and expression of a novel gene activated in early mouse embryogenesis. The EMBO J 7: 673-681, 1988.

5. Brannan CI, Dees EC, Ingram RS and Tilghman SM: The product of the H19 gene may function as an RNA. Mol Cell Biol 10: 28-36, 1990.

6. Szabo PE and Mann JR: Allele-specific expression and total expression levels of imprinted genes during early mouse development: implications for imprinting mechanisms. Genes Dev 9: 3097-3108, 1995

7. Keniry A, Oxley D, Monnier P, et al: The H19 lincRNA is a developmental reservoir of miR-675 that suppresses growth and Igf1r. Nat Cell Biol 14: 659-665, 2012.

8. Poirier F, Chan CT, Timmons PM, Robertson EJ, Evans MJ and Rigby PW: The murine $\mathrm{H} 19$ gene is activated during embryonic stem cell differentiation in vitro and at the time of implantation in the developing embryo. Development 113: 1105-1114, 1991.

9. Rachmilewitz J, Gileadi O, Eldar-Geva T, Schneider T, de-Groot $\mathrm{N}$ and Hochberg A: Transcription of the H19 gene in differentiating cytotrophoblasts from human placenta. Mol Reprod Dev 32: 196-202, 1992.

10. Yu LL, Chang K, Lu LS, et al: Lentivirus-mediated RNA interference targeting the $\mathrm{H} 19$ gene inhibits cell proliferation and apoptosis in human choriocarcinoma cell line JAR. BMC Cell Biol 14: 26, 2013.

11. Kafri T, Ariel M, Brandeis M, et al: Developmental pattern of gene-specific DNA methylation in the mouse embryo and germ line. Genes Dev 6: 705-714, 1992. 
12. Avila L, Yuen RK, Diego-Alvarez D, Penaherrera MS, Jiang R and Robinson WP: Evaluating DNA methylation and gene expression variability in the human term placenta. Placenta 31 : 1070-1077, 2010.

13. Serman L, Vlahovic M,Sijan M, et al: The impact of 5-azacytidine on placental weight, glycoprotein pattern and proliferating cell nuclear antigen expression in rat placenta. Placenta 28: 803-811, 2007.

14. Gao WL, Li D, Xiao ZX, et al: Detection of global DNA methylation and paternally imprinted $\mathrm{H} 19$ gene methylation in preeclamptic placentas. Hypertens Res 34: 655-661, 2011.

15. Bartolomei MS, Webber AL, Brunkow ME and Tilghman SM: Epigenetic mechanisms underlying the imprinting of the mouse H19 gene. Genes Dev 7: 1663-1673, 1993.

16. Creusot F, Acs G and Christman JK: Inhibition of DNA methyltransferase and induction of Friend erythroleukemia cell differentiation by 5 -azacytidine and 5-aza-2'-deoxycytidine. J Biol Chem 257: 2041-2048, 1982.

17. Ji L, Brkic J, Liu M, Fu G, Peng C and Wang YL: Placental trophoblast cell differentiation: physiological regulation and pathological relevance to preeclampsia. Mol Aspects Med 34: 981-1023, 2013.

18. Altieri A, Franceschi S, Ferlay J, Smith J and La Vecchia C: Epidemiology and aetiology of gestational trophoblastic diseases. Lancet Oncol 4: 670-678, 2003.

19. Anin SA, Vince G and Quenby S: Trophoblast invasion. Hum Fertil (Camb) 7: 169-174, 2004.

20. Sibai BM: Diagnosis and management of gestational hypertension and preeclampsia. Obstet Gynecol 102: 181-192, 2003.
21. Bourque DK, Avila L, Penaherrera M, von Dadelszen $\mathrm{P}$ and Robinson WP: Decreased placental methylation at the H19/IGF2 imprinting control region is associated with normotensive intrauterine growth restriction but not preeclampsia. Placenta 31 197-202, 2010

22. Buckberry S, Bianco-Miotto T, Hiendleder S and Roberts CT: Quantitative allele-specific expression and DNA methylation analysis of H19, IGF2 and IGF2R in the human placenta across gestation reveals H19 imprinting plasticity. PLoS One 7: e51210, 2012.

23. Yuen RK, Penaherrera MS, von Dadelszen P, McFadden DE and Robinson WP: DNA methylation profiling of human placentas reveals promoter hypomethylation of multiple genes in early-onset preeclampsia. Eur J Hum Genet 18: 1006-1012, 2010.

24. Yu L, Chen M, Zhao D, et al: The $\mathrm{H} 19$ gene imprinting in normal pregnancy and pre-eclampsia. Placenta 30: 443-447, 2009.

25. Jones PA and Takai D: The role of DNA methylation in mammalian epigenetics. Science 293: 1068-1070, 2001.

26. Larsen F, Gundersen G, Lopez R and Prydz H: CpG islands as gene markers in the human genome. Genomics 13: 1095-1107, 1992.

27. Smits G, Mungall AJ, Griffiths-Jones S, et al: Conservation of the H19 noncoding RNA and H19-IGF2 imprinting mechanism in therians. Nat Genet 40: 971-976, 2008.

28. Walsh C, Miller SJ, Flam F, Fisher RA and Ohlsson R: Paternally derived H19 is differentially expressed in malignant and nonmalignant trophoblast. Cancer Res 55: 1111-1116, 1995. 